\title{
The Life Trajectory of the Finnish Religious Educator
}

\begin{abstract}
Religious education is an integral part of the Finnish National Curriculum, from early childhood to upper secondary level. Comprehensive school instruction combines (religious / secular) traditionbased pupil groupings with common pedagogical approaches and value orientations across traditions, such as respect for cultural and religious diversity, individual difference, and engagement with plurality. Religious education in Finland is currently adapting to new national religious and secular pluralities. In this pedagogically and socio-politically contested space, a distinctive Finnish approach to religious education is emerging which, we argue, reflects tensions between 'old' and 'new' diversities (Vertovec) in a rapidly changing and secularizing Finnish society. Mindful of this complexity, and the importance of professional religious educators in determining curricula change and societal transformation, we use a qualitative life history methodology to assess how Finnish religious professionals view and manage such changes in the light of their own life trajectories. Our findings show the Finnish religious educator coming to personal and professional terms with both curricula and wider societal change, deeply reflexive but also tentative, and uncertain. As such, we conclude that a life trajectory methodology has helped to reveal insights into an often neglected aspect of the story of curricula change, a narrative in which the religious education professional is shown as a critical locus of unresolved tension reflective of wider Finnish society.
\end{abstract}

\section{Introduction}

Large-scale European projects like REDCo have examined in significant ways whether religious education is the source of conflict or a possible source of dialogue, with classrooms a potential locus for inter-religious exchange leading to more socially harmonious and cohesive societies. ${ }^{1}$ With intensified global concerns for urgent answers to the questions of extremism and radicalisation, international terrorism, religious education has too become the subject not only of political but security agendas. ${ }^{2}$ The study found that such tensions are mirrored in the professional and personal life stories of Finnish religious educators.

In this pedagogically and politically contested space we found that a distinctively Finnish approach to religious education inadvertently reflects tensions in Finland's culturally changing, religious pluralizing and secularizing society, modelling this around Vertovec's 3 'old' and 'new' diversities. Mindful of this complexity, and the importance of professional religious educators in effecting curricula change and societal transformation, we use a qualitative life history methodology ${ }^{4}$ to 
assess how Finnish religious educators view and manage such developments in the light of their own life trajectories.

Based on a small-scale $(\mathrm{N}=16)$ sample of leading Finnish religious education professionals our preliminary findings show the Finnish religious educator coming to personal and professional terms with both curricula and wider societal change, deeply reflexive but also tentative, and uncertain. As such, we conclude that a life trajectory methodology has helped to reveal insights into an often neglected aspect of the story of curricula change, a narrative in which the religious education professional is shown as a critical locus of unresolved tension reflective of wider Finnish society.

\section{Religious Education in Finland}

An integral part of the Finnish National Curriculum, the Finnish model of religious education in pedagogic terms consists of school instruction based on or around teaching groups according to the child's 'own' ${ }^{5}$ worldview tradition. The model presently includes curricula for Lutheran and Orthodox RE and eleven minority religions and an optional Ethics instruction. Although so organized, religious education is non-confessional and religious practice is not part of instruction; rather, the approach is plural and non-denominational. ${ }^{6}$ Nationally, $92 \%$ of pupils participate in Lutheran religious education; that is, outside the capital Helsinki area, minority religions are rarely taught. The recently renewed National Core Curriculum for Basic Education $2014^{7}$ (the updated document which came into force in August 2016) outlines the following:

In instruction in religion, life's religious and ethical dimension comes under examination from the standpoint of the pupil's own growth, and as a broader social phenomenon. Religion is treated as one of the undercurrents influencing human culture. Instruction in religion is to offer the pupils knowledge, skills, and experiences, from which they obtain materials for building an identity and a world-view. The instruction prepares pupils for encountering the religious and ethical dimension in one's own life and life of the community. The objective of instruction is a general education in religion and philosophy of life. (p. 202.) 
This general description is followed by more precise objectives for the RE instruction of all religious education groups. These include familiarizing the pupil with his or her own religion, the Finnish spiritual tradition and introducing the pupil to other religions. Furthermore, the objectives state religious education aims to "help the pupil understand the cultural and human meaning of religions” and to educate pupils in "ethical living” and helping the pupils to understand the ethical dimension of religion. ${ }^{8}$

The strengths of this model are traditionally seen in that the perspective to contents is to some extent familiar to children, and through the knowledge on one's 'own' tradition, perspective is gradually widened into understanding 'other' views. From the viewpoint of religious minority traditions, this approach has also been supportive for the development of minority identities, and for immigrant pupils, small group religious education can also help the children bridge 'old' and 'new' home cultures, for example interpreting and constructing 'Finnish Islam' identities, practices and the tradition. ${ }^{9}$ However, those who support the renewal of the RE model in Finland argue that it is too expensive and time consuming for the society, municipality and the school, as (preferably qualified) teachers, (equally resourced) venues, (reasonable) times and (good quality) materials need to be allocated for all groups. Additionally, it has been regarded as particularly difficult to find qualified teachers for smaller groups, as for some groups, there are nearly no qualified personnel in the country. This, together with the suspicions that not all small group teaching actually sticks with the demand for non-confessionality, further problematizes pupils' equality in receiving quality instruction. Thereby, alternative models have being piloted in some schools-which has added some additional turmoil into the already heated societal debate on the aims and purposes of RE.

\section{The Life Trajectory Study}

While many of these cited national and international studies have focused on theoretical and empirical issues related to curriculum aims and their implementation, the socio-cultural and 
political consequences and possibilities of religious education, there are, with one or two rare exceptions ${ }^{10}$ very few analyses of how the religious educator herself responds to such changes. This is somewhat strange given that teachers, academics and researchers in the subject often play such a pivotal role in not simply the analysis but the implementation of curricular change. Using wellestablished life history research methods, with its emphasis upon the life trajectories of educationalists ${ }^{11}$ with those interconnected qualitative educational research approaches which put biography, narrative and participant stories to the fore, ${ }^{12}$ this study explored the life trajectory of the Finnish religious educational professional.

\section{Research Question}

Motivated to uncover in preliminary ways how these religious education experts - experts in the sense they are in many ways charged with the implementation of curriculum change - coped with adaptation to the Finnish religious education curriculum in the midst of acute societal plurality, in Vertovec's ${ }^{13}$ terms the 'old' and 'new' diversities, we have examined the following research question:

\section{What kinds of approaches to Religious Education do Finnish teacher educators and researchers of Religious Education hold in terms of the aims of $\mathrm{RE}$ and the suitable model for reaching these from the perspective of their careers and personal life trajectories?}

In order to answer this question, we used a standard method of qualitative educational research, the interview, placing the emphasis upon the stories presented by interviewees as a way of understanding their professional responses to pedagogical innovation in the light of socio-cultural and religious plurality. While we placed respondents' life stories, the trajectory of their personal and professional lives to the fore, without attempting to impose theoretical or other frameworks, the study was mindful - as were the participants - that the entire process of professional engagement 
with these developments had always a larger scale, a macro-political context. In this sense, even in their respective local settings, and despite the distinctiveness of the subject in Finland, neither Finnish religious education nor the professionals at the forefront of curricular change are immune or can be isolated from national and global processes of nascent patterns which have profoundly affected the perceived potential roles of religion in education. This required accommodations on the part of our Finnish religious education professionals' often impressively deep levels of personal and professional reflexivity. But it also brought tensions where accommodation to change within and beyond the (religious) educational system jarred or even clashed with their life experience and their expectations of and for religious education. Mindful of such sensitivities the study was throughout conscious of the need not to enter into engagement with participants with anything other than a spirit of genuine enquiry in order to let their voices be heard and their life stories be told.

\section{Data Gathering}

The data were gathered by the first author through 16 e-mail interviews as well as two further, individual face-to-face interviews with Finnish RE professionals. The outline for both data gathering techniques was the same, and the face-to-face settings thus enabled the participants to wider elaboration of their ideas, and the researcher to ask further questions on their responses. The original e-mail cover letter included the same interview outline attachment in two alternative forms: (a) as a printable Word document for filling in, printing and sending to the researcheranonymously, when desired-either through the Helsinki University (free of charge) mail system or through post (from other parts of the country), or as a reply to the original e-mail with the completed Word questionnaire as an attachment (where the respondent would be identified by the researcher), and (b) as a list of the same questions included in the e-mail body text that could be sent back (completed with replies) via e-mail. The option to return one's answers anonymously was utilized by none of the respondents; everyone responded by e-mail. As a research field, RE in 
Finland is small, thereby it is likely that all respondents would have at least recognized the researcher's name, and most of them would know her personally. Hence, some initial trust had been established already before the present enquiry, which shows both in the way of returning the responses to the politically "hot" topic with respondent information, and also in the width and depth of the data gathered through a rather simplistic measure and means. As a survey to a more general, “anonymous” population, such measure would not be likely to work equally well, as such open questions are easy to leave blanc or answer very briefly. Here, on the contrary, many of the respondents had visibly spent a lot of time and effort in responding.

\section{Tools}

The interview outline consisted of the following sections and themes: (1) Background information (age, gender); (2) Individual account on Religious Education in one's personal life trajectory (RE related education, work history incl. present occupation); (3) Respondent's views and personal experiences related to the main aims of RE (a) in relation to child's growth and development, and (b) from societal perspective; (4) Respondent's views on what kind of RE model would best serve in supporting pupil's growth and development, and why; (5) According to respondents, what strengths and weaknesses do the following have: (a) presently utilized RE model (instruction based on pupils’ affiliation), (b) integrated RE model where whole class is taught together, and (c) would a combination of these models be a good solution? If so, what kind of combination or 'hybrid' would the respondent suggest? (6) How have their own views on the aims of RE and the RE model altered during the years? Which factors have, according to the respondent's views, influenced this change? 


\section{Sample}

The data includes responses from RE faculty representatives from universities as well as various other institutions and establishments and university practice schools. ${ }^{14}$ The altogether 16 respondents were of the ages 30-53 (average age 41.25 years) and included four males and twelve females. The sample includes professors, university lecturers, junior or post doc level researchers as well as other RE professionals holding positions in different educational or RE organizations, some of which are related to churches or religious communities. Out of the respondents, all except one (also qualified as an RE teacher) hold at least a MA degree either in Education, Theology, or both; 10 out of the 16 hold a doctorate $(\mathrm{PhD})$ in an RE related area (Theology or Education), and 3 others are in the process of completing their $\mathrm{PhD}$.

\section{Ethics}

The study followed the ethical guidelines of the Finnish Advisory Board on Research Integrity ${ }^{15}$ for the collection, storage and dissemination of data gathered using human subjects. All participants in the study were adult professional religious educators, often in positions of some seniority and responsibility. These professional characteristics gave weight and authority to responses, and indeed further confirmed a sense prior to the study that there were no likely ethical issues around imbalances of power or safety to arise.

However, one especially notable emergent ethical aspect of the study was that of anonymity and in a relation to this, the safeguarding of confidentiality in reporting the findings. Thus, due to the relatively small size of the national religious education community in Finland, especially at a senior level (for example, university-employed staff at all grades from post-doctoral to professor), in the reporting of the data, detailed information about each respondent was not connected to their direct quotes in order to maintain confidentiality and ensure anonymity. In order further to ensure 
confidentiality and anonymity, the study was also assiduous in not matching respondents' replies to precise details of age, gender, and profession.

\section{Analysis}

While standard qualitative approaches to content analysis ${ }^{16}$ were applied to the transcribed interviews, in its focus on life history and trajectory the approach taken in terms of analysis put the narrative of the participant to the fore. Thus while a single interview format for each participant was used there was much scope during each conversation for the narrator of their life story to interweave personal and professional narratives into a thematic whole. While thematically guided by the study's core research question, the interviews, the conversations - as life history research may frames them - in terms of responses were able to be arranged into emergent themes. It is we think a mark of the strength of the life history approach as well as the evident topicality of this sociopolitically heated theme that these Finnish religious education professionals were willing to speak so frankly and openly about not simply their academic and professional positions but their personal and life-positionings. Compatibilities and tensions between professional persona and personal standpoint showed through our analysis the rich potential of the life trajectory approach. We cannot say that on the basis of small-scale study, though with authoritative voices in the field, that our analysis is either complete or final. And yet we are strongly convinced that our core research question has produced a methodologically sound analysis, which we have stated in our introduction; that is a narrative of the Finnish religious educator coming to personal and professional terms with both curricula and wider societal change, deeply reflexive but also tentative, and (albeit at times only) uncertain. The analysis, as for the life trajectory methodology, has helped to reveal insights into an often neglected aspect of the story of curricula change, a narrative in which the religious education professional is shown as a critical locus of unresolved tension reflective of wider Finnish society. These general findings are presented firstly, and for reasons of space, briefly here through a 
multiplicity of voices, mere snippets of stories, but in order to draw together what for us was a collective story, with personal and individual differences, through one life trajectory story, that of 'Paju', a unisex name meaning 'Willow' to incorporate, include female and males voices through our one anonymized but true-to-professional-life character.

\section{The Life Trajectory of the Finnish Religious Educator}

\section{General Findings}

The aim of the overall study was to examine the kinds of approaches to Religious Education that Finnish teacher educators and researchers of Religious Education hold in terms of the aims of RE and the suitable model for reaching these, from the perspective of their careers and personal life trajectories. The educational and occupational trajectories of the respondents typically included an MA in Education and/or Theology, and a completion of a $\mathrm{PhD}$. In addition to this, the respondents typically hold some years of teaching experience, either in secondary school RE (in primary school RE is taught by class teachers, whereas in lower and upper secondary school it is taught by subject teachers), or as ECEC, preschool, or primary school teacher (in all of which RE is only one of the taught content areas), followed by more research on RE and related themes, and then teacher training or in-service teacher training experience. Several of the participants have also been involved in developing either the national curriculum for religious education in different levels, ${ }^{17}$ or have been developing widely utilized books or other teaching materials for prominent national publishing houses.

A lot has changed: this has been influenced by the fact that besides merely the theoretical examination I've also examined the practical approach. E.g. in terms of educational philosophy, I'd still be a sturdy supporter of the model based on child's own religion ...

We find the tension evokes by this change provoking this participant to questioning their own judgement on matters of value and principle:

I don't know if I still ought to be, in principle ... 
The tension evoked by curricular change is perceived clearly as mirrored wider societal-culturalpolitical upheaval:

... but the knowledge on educational field, the following of the societal situation and the deepening of my understanding on the integrated model have directed my thinking into another direction ...

The tension is felt as a personal and professional responsibility, even a burden:

I feel responsibility on the future of the subject (that I cannot hang myself into supporting a model for which I cannot see a future even if it would better apply to my thinking).

To us, this highlights how societal pressures towards the RE in Finnish curricula in the first place many of these professionals see that the main issue is to maintain the subject in schools, and for ensuring that aim is reached, they are willing to give in somewhat to what the instruction could be like in the "ideal world" can be seen from this data extract.

When it comes to the changes in their views and personal experiences related to the aims of RE, and the RE model, the data includes factors that have altered the views and opinions of these professionals gradually, though societal change and the development of professionalism (work experience, gaining deeper understanding of the needs of the pupils), or personal life experiences (e.g. extended travel in different continents). As regards the gradual development of opinions into a different direction, many have mentioned societal change in Finland, and the increasing pluralism and the increasing prominence of religious diversity in the society. More precisely, the respondents mention that their views have been influenced following particular "turning points" or meaningful life experiences, such as through personal contacts or co-operation with members of minority groups (1 respondent $)^{18}$ or convincing arguments by other people in mutual in discussions (3); extended international travel (1) or other international influences (1). Also work experience was seen meaningful by many, whether at the university or in the everyday of schools (6), and the teaching position including the curriculum renewals also influencing the personal "updates" in educational aims related to RE (1). Furthermore, it was mentioned that one having to justify her own position to others (1), increasing one's knowledge on the possible alternatives (e.g. further education) (4) or research on the topic (own / other) (3) can crystallize one’s personal views. 
Several respondents also mentioned that societal change (3) and increased secularization (1) and societal pluralism (4)—seen as causing more complexity in organizing the RE practicalities in schools. These were causing pressure for renewing RE (2) and also the risk of marginalization of $\mathrm{RE}$ as a subject or that RE will be removed from the curriculum if the subject is not developed further (4). Thereby, one of the reasons for the supporting of changes was that the respondents' main motivation in keeping RE in the curriculum in the first place (3). Finally, four (4) respondents said that there has not been a significant change in their views about RE throughout years (4). The reasons for not adopting a different view during work trajectory were explained for instance in the following way:

[My view] has remained rather similar. I haven't really been that interested on the discussion on the RE model, as it is usually triggered by structures and then the actual justifications are elsewhere than in the pedagogics. But perhaps I've become more actively aware of the importance for recognition of the diversity within a particular religious tradition and thereby seen opportunities for providing stronger support for dialogue skills also in the segregated instruction.

This quote illustrates that despite heated debate in the topic, not all RE professionals, even those in more senior levels, want to give in to the societal pressures. Furthermore, besides highlighting the fact that sometimes the professionals may not necessarily alter the direction of their thinking altogether but rather gain more in-depth elements into their perspective, this data extract is also interesting in bringing added emphasis on the dialogue skills, another much highlighted topic in the societal debate on the Finnish RE in the recent years. This is thought-provoking from the perspective that although it is an important element in the guidelines, too, it is naturally merely one of the aspects in the requirements sets for the subject nationally.

Another professional says, in similar lines:

For me, the model is not the question, but that RE would at least be taught in the comprehensive education, and that it would, in accordance, be comprehensive. The contents hold greater significance to me than the model. Mutual worldview education feels threatening at present because I'm not sure 
whether they'd succeed with the [RE] curriculum, or I don't know who would do it or which instance? I do trust the National Board of Education.

Also this professional brings the discussion close to heart by talking about the "greater significance to me” as well as how the mutual worldview education "feels threatening at present”after already initially beginning with “[f]or me..” Hence, this quote illustrates the personal significance of RE as a subject to many of these professionals.

In the following, we will present now the life trajectory of 'Paju' for insight into one professional and personal life trajectory through the quandaries of contemporary Finnish religious education.

\section{'Paju': The Life Trajectory of a Finnish Religious Educator}

'Paju' opens the conversation with a brief personal account on the topic by explaining his own theoretical contributions to the field, as well as saying: “And so then I've got quite a lot of the kind of more pragmatic processing of the topic.” Paju has experience in teaching RE both at school and in the university level. Similar trajectories were shared by several of the respondents with a "first career” as an RE teacher, followed by research and university level teaching.

As regards the competences for global citizenship, Paju believes in RE for several reasons: "Strengthening moderate and wide interpretations of faith and combatting extremism. Bringing up critical citizens. Dialogue between religions.” Paju also notes the interrelatedness of the current situation related to the challenges of RE with what Vertovec ${ }^{19}$ calls 'new' diversity, saying: “This is sort of, we have, this situation derives from the short history of migration in Finland and that.”

A background in theology, which in the data was often preceded by active participation in Lutheran Church's youth work activities as well as confirmation camp participation and later assistant camp councillor [ 'isonen'] duties, is visible in several accounts of the respondents' views about the main aims of religious education in schools. Paju holds several university degrees, with his/her background in Theology, with increased educational and RE perspectives having gained importance in Paju's work later. The strong theoretical competence in Theology is visible in many 
of Paju's answers, like when talking about the meaning of RE for the growth and development of the child:

Everything is not [--] deflated in the here and now, so what is there then-there can be different theories about that. And the recognizing of the multitude of different perspectives: that there are, in fact, varied justified perspectives to many questions, ethical and others. That it may not necessarily be taught in Maths that there are right and wrong answers.

Hence, Paju recognizes the importance of making the children think about the nature of knowledge; what can be known; which questions can be answered with a more definitive answers, and then again, which questions would gain a whole spectrum of truth claims from different traditions and individuals. He continues elaborating this topic from the perspective of an individual:

People do also have the kind of blurred situations or something. Or even sometimes the sort of issues that one cannot really choose the option that one knows is the one that should be chosen.

This leads him to sum up what he sees as the "take home value" of RE from the perspective of an individual child and her developmental trajectory:

Overall, from the perspective of child's growth and development, what are the transferable skills that $\mathrm{RE}$ as a subject provides to the children? [--] I do think that these same aims can in principle be found in other traditions.

Like most respondents, Paju believes that current RE model have particular strengths and weaknesses. Other informants present their perspectives from the viewpoints of various stakeholders such as religious minority background pupils. Several respondents also refer to the recent study by Inkeri Rissanen ${ }^{20}$ on the Finnish Islam RE, when justifying their views on these questions. Through Rissanen's findings, these professionals refer to the importance of minority RE in the supporting of the pupils' religious identity, and inter-connectedness with citizenship or “Finnishness” construction. Referring to Rissanen’s study, Paju says in the interview:

[T]he point is that there is a place where they can experience that 'We are good Finnish Muslims'. And ponder what that means to be a Finnish Muslim, sort of a combination of citizenship and Islam. [--] And 
that [aim] won't be reached in any way in this kind of worldview education. [--] In terms of minority politics [--] Educating critical citizens.

Paju thus believes that the present RE model would be beneficial from societal perspective for both the educating of critical citizens and for the fact that minority RE can work as a means of “interpreting Finnishness” into the minority traditions_-and vice versa.

The informants in the study generally acknowledged several challenges in the present model as regards to its practical implementation (e.g. expense, segregation of pupils to various classrooms). Similarly, the mutual, integrated model was seen to have both pros and cons; e.g. the management of schedules and other practicalities, and dialogue between religions possibly more practical to organize. However, many of the challenges were seen to relate to these exact issues, for example the weakening of both minority and majority rights to one's 'own' tradition, and the fear that the subject matter would be weakened with a more general approach. Furthermore, an important challenge was seen in how such mutual instruction would, in fact, be implemented, and what exactly is even meant by this much utilized buzz-word of 'dialogue'. Paju says:

[T] he dialogue between religions [--] is the challenge of our time. And it does not of course mean thatno explicit dialogue between religions; that a Muslim sits on the other side of the table and the Christian on the other and then it's sort of carried out. [--] It only means that you can understand that this other person has another religion, and respect that. These are the skills in religious dialogue, although these wouldn't realize in any sort of verbal explication.

Hybrid models combining elements of both the segregated and the integrated ones, are also offered by the respondents. The following extract in Paju's interview gathers together many views also present in the other answers:

[T]here's a problem embedded in this one naturally: what is that "own" tradition? [--] especially small children, the "own" the sort of "own" background tradition narrative, the knowledge on that offers this sort of a bouncing platform from where to then be able to see where does one come from and how do we encounter others. Of course it could, in theory, be done through a mutual RE instruction with a strong emphasis on the positive freedom for religion, when, if the mutual instruction principle would be the 
teaching of the “own” religion. And everyone would be treated individually then, even if they would all sit in the same space. But in practice it of course feels rather impossible to implement it in one classroom, directed by one teacher. [--] But then again I also think that the whole school culture should support the dialogue, create the opportunities for encounters also. [S]ay, in upper secondary, for example sort of, it could be a mutual subject. [--] In lower secondary it could be a mutual subject, but not in primary school.

In terms of the development of (a) theological / religious education perspectives; and (b) encounter with religion directly (ethnographic experience) —in Paju’s theoretical and practical life trajectory, there are several significant events brought up in the interview. As mentioned above, Paju's theoretical thinking derives from his strong theological foundation combined with practical experience of teaching in different educational levels. Paju mentions that university teaching has been useful for processing and conceptualizing matters related to RE. Paju went on several trips to different parts of the world that significantly influenced in the widening of his horizons in the professional sense. Paju says:

I wouldn't be the same person that I am now if I hadn't been in [country] and started [year] to study theology and sort of gone in [country] backpacking, through which I got sort of challenged; that my sort of ways to conceptualize the world were completely inadequate.

Moreover, Paju mentions co-operating with minority representatives and groups both in Finland and internationally as significant experiences that have increased his understanding of different stakeholders. Also to the fore in Paju's narrative consciousness here are how such viewpoints are informed, shaped and perhaps even manipulated by the permeation of Finnish religious education by identity and minority politics.

\section{Discussion and Open Conclusion}

Bardi et $\mathrm{al}^{21}$ examine value stability and change as the adjustment of personal values to life transitions. They define value socialization as the process in which "people may gradually acquire the values that are regarded as appropriate and desirable in the life setting." Examining how 
individuals' values fit the new social settings during life transitions, the present study found that Finnish religious professionals point to this development. Such accommodations and adaptations are generally fraught with difficult to resolve quandaries. Finnish RE professionals found themselves between models of inclusive accommodation to diversity, to 'old' and 'new' diversities, and a personal sense of commitment to a lived experience of religion or secularity.

On the evidence, the life trajectories of Finnish religious education professionals indicated many similarities, including those supportive of radical religious education alternatives. But the dominant concern were shared, collective, objectives for children's learning their fundamental well-being, as well as concern for wider societal coherence and wider societal well-being. The decision making process here, the professional-personal accommodation, is as interesting for the researcher as it is challenging for the participant. All seem to address a critical question: How do I cohere my personal formation and presently, historically-formed life- and worldviews in professional context? Many saw the importance of societal changes important, notably in adjusting subject aims and objectives to the practical implementation into societal conditions, including competencies needed for children to live cohesively in contemporary society and the Finland of the future.

Thereby, the opinion changes described in the data are very much of the nature described by Bardi et $\mathrm{al}^{22}$ as theoretically meaningful to these religious educational professionals. Furthermore, such value socialization in context also suggested that many of these experts would philosophically and educationally prefer the present 'own worldview approach' or a hybrid model. If some regard the mutually inclusive religious education as the only plausible solution for future, it is with a view to the perceived risk of otherwise marginalizing or even removing religious education altogether from Finnish schools.

Important perspectives were brought up by several respondents on matters beyond the practical organization of religious education in schools. Religious education needs to be critically examined as a 'scientific', secular position as such is not neutral. Similarly, questions were raised about the 
selection of and balance between different traditions and other elements included in the taught contents of the subject, including time allocations for diverse and divergent perspectives within and across both religious and secular worldviews. We may say that such decisions reflect the educational values and aims of society and, critically, educational policy makers. Within this context, the life trajectories of religious education teachers point to their own life-long formation as teachers. ${ }^{23}$ But the life trajectory of the Finnish religious education professional provides also a rich seam of insight for the educational researcher, insightful of societal, indeed political, as much as educational processes. In a circular sense, such life trajectory research may also provide for policymakers in Finland and elsewhere a model for obtaining a nuanced and more sensitively-attuned sense of those responsible for curriculum and societal change. If the Finnish religious education professional in some senses mirrors the wider tensions in society between 'old' and 'new' diversities, then too, in an ideal sense, for society such life trajectory research provides valuable opportunities for self-understanding, providing insights into society’s own religious and secular transformations.

\footnotetext{
${ }^{1}$ Robert Jackson, "The Interpretive Approach as a Research Tool: Inside the REDCo Project", British Journal of Religious Education, 2011, 33 (2) 189-208.

2 Liam Gearon, "The Counter Terrorist Classroom: Religion, Education, and Security", Religious Education, 2013,108

(2) 129-147.

Robert Jackson, "The Politicisation and Securitisation of Religious Education: A Rejoinder", British Journal of Educational Studies, 2015, 63 (3): 345-366.

${ }^{3}$ Steven Vertovec, "Introduction: Migration, Cities, Diversities 'Old' and 'New', In S Vertovec (Ed.) Diversities Old and New: Migration and Socio-Spatial Patterns in New York, Singapore and Johannesburg, 2015, 1-20.

${ }^{4}$ Ivor F. Goodson and Pat Sikes, Life history research in educational settings: Learning from lives. Buckingham and Philadelphia: Open University Press, 2001.

Pat Sikes and Judith Everington, in Mandy Robbins and Leslie J. Francis (eds.) The Empirical Science of Religious Education, 2016, pp. 63-73.

${ }^{5}$ Based on the formal membership in religious communities, if any, or the decision of the parent(s)-mother, if there is no agreement between the parents on this-, with different opportunities to choose the RE instruction participated, or opt out and choose Ethics, depending on the particular membership or lack of any. For example, the formal members of the majority Evangelical Lutheran Church are required to attend the Ev. Lutheran RE instruction, although many of the families nowadays are increasingly secularized, and the child and/or the parents would prefer the "secular" Ethics alternative. Those without a religious membership, on the other hand, are free to choose between these two options. In any case, and as already the parents already hold elements of more than one "tradition" in their worldviews, besides the children being influenced by other people, the media, and so on, in their growing-up context, and gradually constructing their personal views in relation to these and through their own agency, the definition of one's "own" religion in the RE instruction setting can be seen as rather problematic.
} 


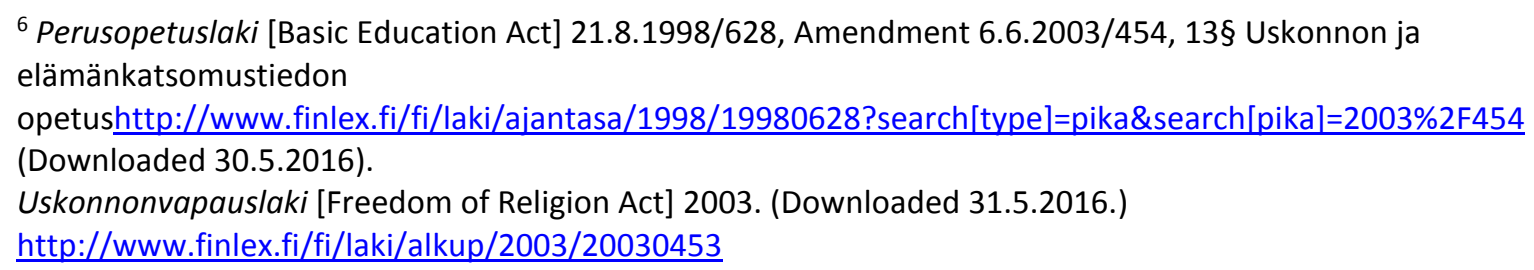


${ }^{23}$ Inkeri Rissanen, Elina Kuusisto and Arniika Kuusisto, "Developing teachers' interreligious and intercultural competences: Case study on a pilot course in teacher education". Teaching and Teacher Education: An International Journal of Research and Studies, Vol. 59, Oct 2016, 446-456. 